\title{
A Multimethod Approach for Creating New Business Models: The General Motors OnStar Project
}

\author{
Vince Barabba \\ General Motors Corporation, Corporate Strategy and Knowledge Development, 400 Renaissance Center, P.O. Box 400, \\ Detroit, Michigan 48265 \\ Chet Huber • Fred Cooke \\ General Motors Corporation, OnStar Headquarters, 1400 Stephenson Highway, Troy, Michigan 48083 \\ Nick Pudar \\ General Motors Corporation, Corporate Strategy and Knowledge Development, 400 Renaissance Center, P.O. Box 400, \\ Detroit, Michigan 48265 \\ Jim Smith \\ General Motors Corporation, OnStar Headquarters, 1400 Stephenson Highway, Troy, Michigan 48083 \\ Mark Paich \\ Decisio, 320 West Cheyenne Road, Colorado Springs, Colorado 80906 \\ vince.barabba@gm.com • chet.huber@onstar.com • fred.cooke@onstar.com • nick.pudar@gm.com \\ - jim.smith@onstar.com・m.paich@att.net
}

\begin{abstract}
We developed a multimethod modeling approach to evaluate strategic alternatives for GM's OnStar communications system. We used dynamic modeling to address some decisions GM faced in 1997, such as the company's choice between incremental and aggressive marketing strategies for OnStar. We used an integrated simulation model for analyzing the new telematics industry, consisting of six sectors: customer acquisition, customer choice, alliances, customer service, financial dynamics, and dealer behavior. The modeling effort had important financial, organizational, and societal results. The OnStar business now has two million subscribers, an 80 percent market share of the emerging telematics market, and has been valued at between $\$ 4$ and $\$ 10$ billion. The OnStar project set the stage for a broader GM initiative in service businesses that ultimately could yield billions in incremental earnings. Most important, OnStar has saved many lives that otherwise would have been lost in vehicle accidents.

(Industries: communications. Transportation: automotive.)
\end{abstract}

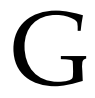
eneral Motors (GM) assembled a project team consisting of the authors of this paper to develop its OnStar telematics business. Telematics is the provision of communications services to cars, including crash notification, navigation, Internet access, and traffic information. We used a multimethod modeling approach to design the OnStar business model and to analyze the fundamental strategic decisions GM faced in 1997. We explain the modeling process and some specifics of the model that we used to analyze the strategic choices, and we present the financial, organizational, and social impacts the project created.

OnStar is GM's two-way vehicle communication system that provides a variety of services that enhance safety, security, entertainment, and productivity (Figure 1). The vehicle communicates with either an automated system, called the virtual advisor, or with a human advisor through a cell-phone connection. Two-way 


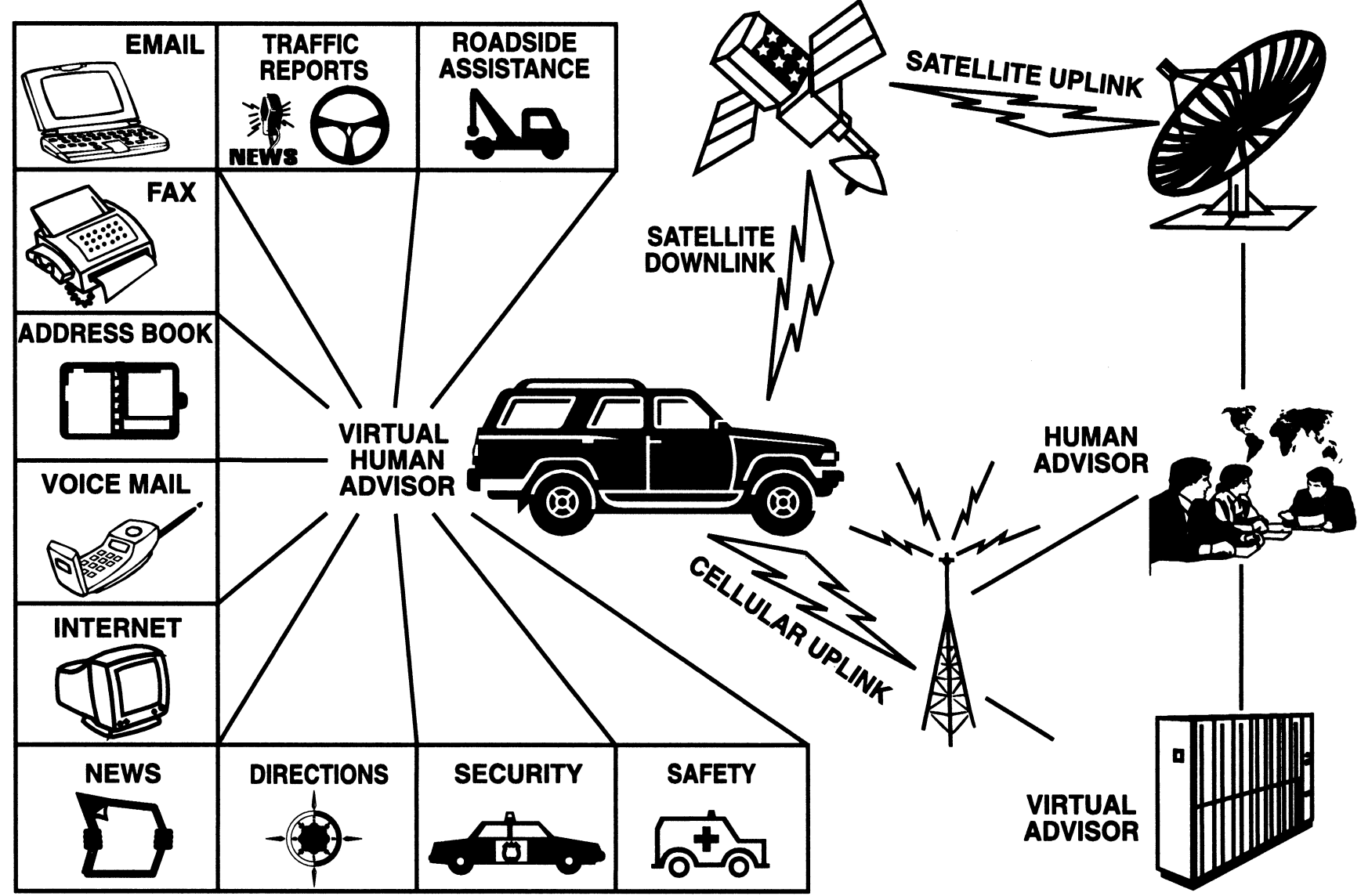

Figure 1: OnStar provides safety and security, Internet, and communications services.

communication enables safety and security services, such as crash notification, in which the call center is notified if the vehicle crashes or the airbag is deployed. A built-in global positioning system (GPS) precisely locates the vehicle and, if necessary, the call center dispatches emergency services to the accident scene.

Two-way communication facilitates a variety of other services that provide information and enhance the user's productivity. For example, users can obtain real-time traffic information through the virtual advisor in most major cities. In addition, they can access content, such as the Wall Street Journal, and have it read to them. Many other services have either been implemented or are currently in development.

OnStar began in 1994 as a promising communications technology. A GM engineering group proposed Project Beacon to test the application of advanced communications technology in GM vehicles. To test the concept, in 1996, GM made OnStar available as an option on some Cadillac models. The services at that time were limited to safety and security and a few other features, such as remote door unlocking. The OnStar system required complicated installation by the dealer, costing about $\$ 1,300$. The high cost and hassle of installation limited customer acceptance, but market research showed that buyers found the system extremely valuable and that the customer retention rate was very high. Some senior GM executives believed that with the appropriate strategy, OnStar could become an important product.

\section{Fundamental Decisions in 1997}

In 1997, GM faced fundamental strategic decisions with respect to OnStar. First, GM had to decide whether to view OnStar as a car feature or as a service 
BARABBA ET AL.

The General Motors OnStar Project

business. The default and safe strategy was to market OnStar as a car feature that would improve vehicle safety and security. GM had decades of experience with new car features and had well-developed models for pricing and packaging vehicle options.

An alternate strategy was to view OnStar as a service business that could contribute greatly to GM's profits (Figure 2). The OnStar business would collect monthly subscription fees in exchange for a portfolio of services. The business would be responsible for acquiring, developing, and retaining customers and would provide customer service. In contrast with the vehicle business in which GM interacts with customers infrequently, the service business would put customers in touch with GM with every use of OnStar.

GM would have to choose between an evolutionary and a revolutionary strategy. If it decided to create an OnStar service business with the evolutionary option, GM would take a cautious approach to the telematics market. In 1997, the telematics category barely existed, and no vehicle manufacturer had invested in it aggressively. GM faced almost complete uncertainty about technological approaches, major competitors, and what competitive and complementary technologies would emerge among the Internet, digital cellular services, and hand-held devices, such as PDAs.

A reasonable approach to such pervasive uncertainty would be to postpone any major investments until the picture became clearer. GM could run a portfolio of small technological experiments to develop and preserve its options until the direction of the market became clearer. Once the situation was better defined, GM could be a fast follower that could profit from the mistakes of bleeding-edge competitors. In the Internet field, for example, the blood of failed first movers, such as WordPerfect, CPM, and VisiCalc, and various Internet companies is splattered all over the battlefield.

Specifically, if GM took an overly aggressive approach, it might make large investments in vehiclecommunications hardware and infrastructure and then fail to recover the costs because of low customer demand. A good example of the failure of an aggressive strategy in communications is Iridium's launch of satellites that cost several billion dollars. The system never attracted many subscribers, and Motorola was forced to write off most of its investment. On its face,

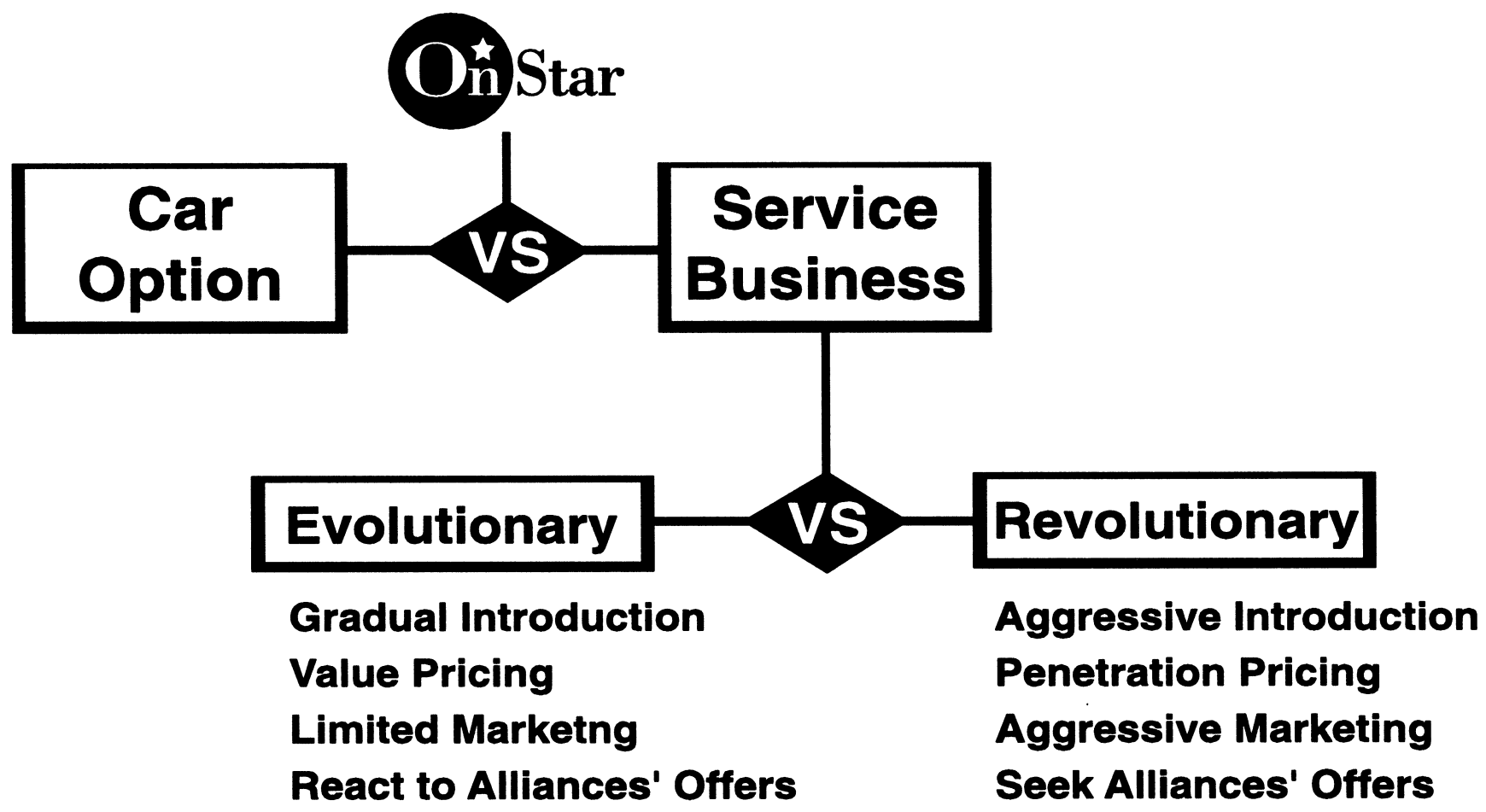

Figure 2: In 1997, GM faced fundamental strategic decisions for OnStar. 
the conservative strategy is sensible, and indeed, both Ford and DCX have taken a cautious approach; neither will launch a telematics service until 2003.

On the contrary, in some cases in the automobile industry, the go-slow approach has served firms badly. Auto companies missed the opportunity to be major players in the cell-phone business even though 60 to 80 percent of cellular minutes are consumed in cars and even though some auto companies understood the potential for cell phones years before demand exploded. The cell-phone analogy is well known at GM. A second example of go-slow failure was Detroit's sluggishness in responding to consumer demand for small, energyefficient, high-quality vehicles in the 1970s.

GM's second option was to choose the revolutionary strategy of preempting the market. In this strategy, GM would move quickly to build a large installed base and gain the cost advantages and network externalities that come from being the earliest and biggest player. Network externalities result from a process through which, as more people adopt a service, the service becomes more valuable to both existing and potential customers. There is evidence that the get-big-fast strategy can be very successful. The literature on firstmover advantages, while mixed, provides examples in which preemptive strikes have generated big payoffs (Gurumunrthy et al. 1995). In addition, economic analysis demonstrates that properly managed network effects can create a long-lived competitive advantage (Shapiro and Varian 1999).

GM faced a strategic choice: should it follow an evolutionary wait-and-see strategy or should it make a revolutionary move to develop and preempt the telematics market? The choice was difficult because the market did not exist and data were scarce. In addition, GM had minimal experience in subscriber service businesses, so its senior management had limited intuition about which direction would be better. The preemptive strategy would require a huge investment; failure of the preemptive strategy would be costly. On the other hand, its success would bring large returns.

\section{Modeling an Industry That Did Not Exist}

GM formed a project team (this paper's authors) to consider alternative strategies for OnStar. GM makes important strategic decisions through the dialogue decision process (DDP). DDP consists of four stages to reaching agreement on decisions: framing, alternatives, analysis, and connection (Figure 3). At each step, the project team interacts with the decision board that is responsible for actually making the decision and committing resources.

Dynamic modeling can be a part of each stage. For example, in the alternatives phase, analysts often use

\section{In 1997, the telematics category barely existed.}

models to suggest hybrid strategies that combine the original alternatives. In the analysis phase, they use dynamic models to calculate ranges for important business variables, such as cash flow and market share.

The OnStar case was difficult to model. In the vehicle business, GM has decades of experience and plentiful historical data. Modelers can build on a wealth of previous analyses and examples of best practice. The OnStar business was very different in that the telematics market did not exist and no one had experience or historical data.

To cope with the inherent uncertainty, we needed a modeling process that would allow integration of various methods and data sources. Our method had to be flexible enough to absorb a wide variety of inputs based on judgment, historical analogies, market research, and other sources. Our chosen modeling approach integrated concepts and techniques from several management sciences approaches:

(1) System dynamics was useful in two important ways. First, the stock-flow structure used in system dynamics provided a good foundation for the physics of customer migration from one state to another. For example, the model included structures that tracked the flow of customers from unawareness, to adoption, to churn (loss of customers), and to possible resubscription. Second, the feedback perspective used in system dynamics was very helpful in modeling the network externalities that are crucial to the telematics market.

(2) Conjoint analysis was used to calibrate the consumer choice relationships that govern consumer adoption of OnStar.

(3) Dynamic optimization was used to assess the 


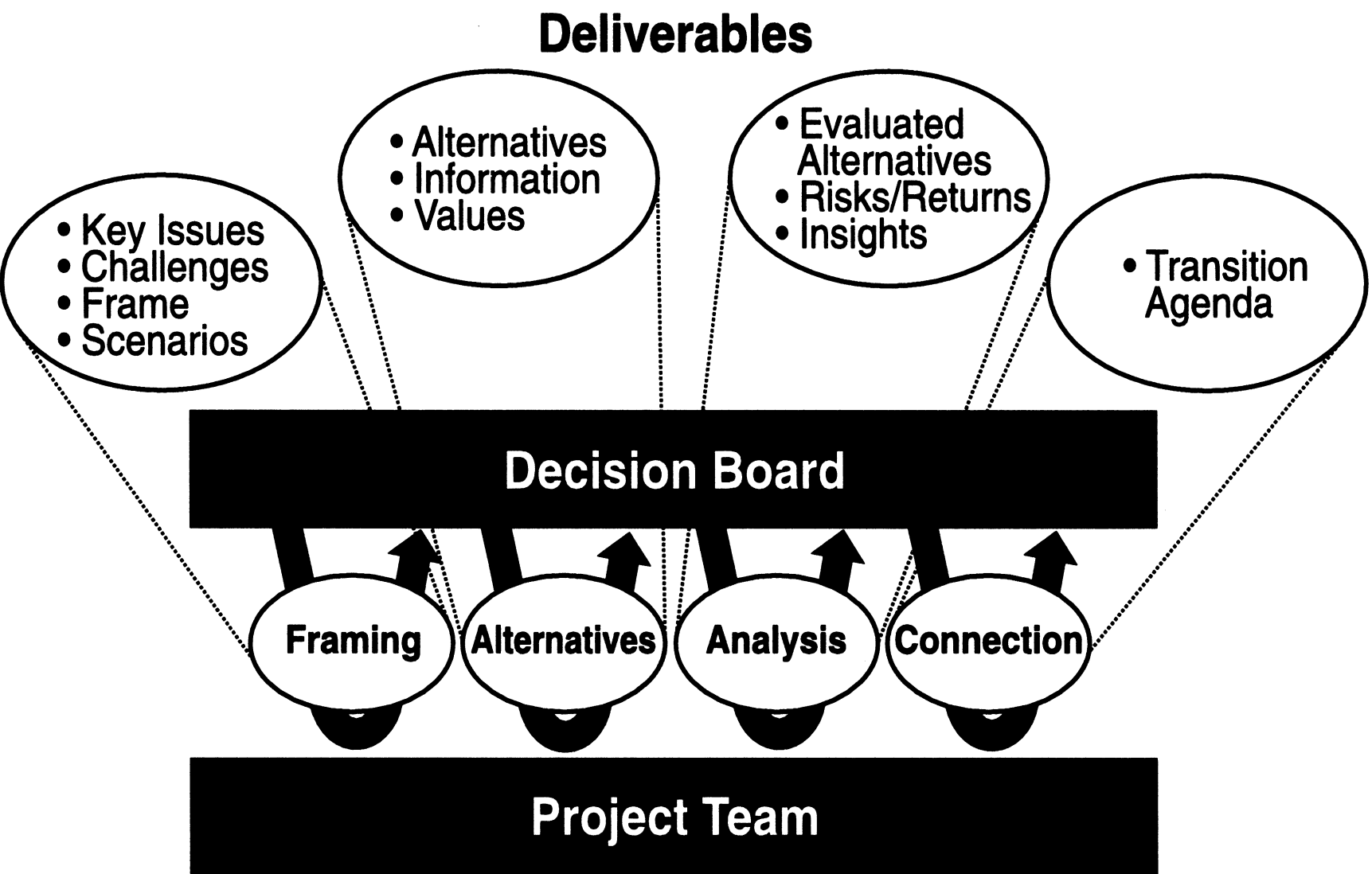

Figure 3: Dynamic modeling is a part of the GM strategic decision process.

correct magnitudes for price and for spending on marketing.

(4) Diffusion models and the literature on previous studies of product diffusion helped us to understand the impact of market spending, word of mouth, price, and product innovation on OnStar adoption.

(5) Concepts from lifetime customer-value analysis helped us to analyze the impact of churn and customer recapture.

(6) The real-options approach was useful for decomposing the decision to expand OnStar into a set of smaller, less costly steps. As it implemented each step, GM had the option of taking the next step if the outcome of previous decisions was favorable.

\section{The Integrated Simulation Model}

A simulation model was our core tool in the OnStar strategy project (Figure 4). It had six key sectors: customer acquisition, customer choice, alliances, customer service (which we discuss in more detail), finances, and dealer behavior. The financial sector calculated financial metrics, such as revenue, cash flow, and profit. The dealer-behavior sector dealt with issues of how dealers made customers aware of OnStar and how much sales effort they expended. The sectors interact over time to generate time series for such important business variables as market share and cash flow.

\section{Customer Acquisition and Retention}

The customer acquisition and retention sector of the simulation model describes the inflows and outflows of OnStar subscribers. The model builds on concepts from the literature on lifetime customer value by explicitly representing the causal mechanisms responsible for subscriber acquisition and churn. Since the accumulated number of subscribers produces monthly revenue directly through the monthly subscription fee, we could use the model to evaluate the financial 


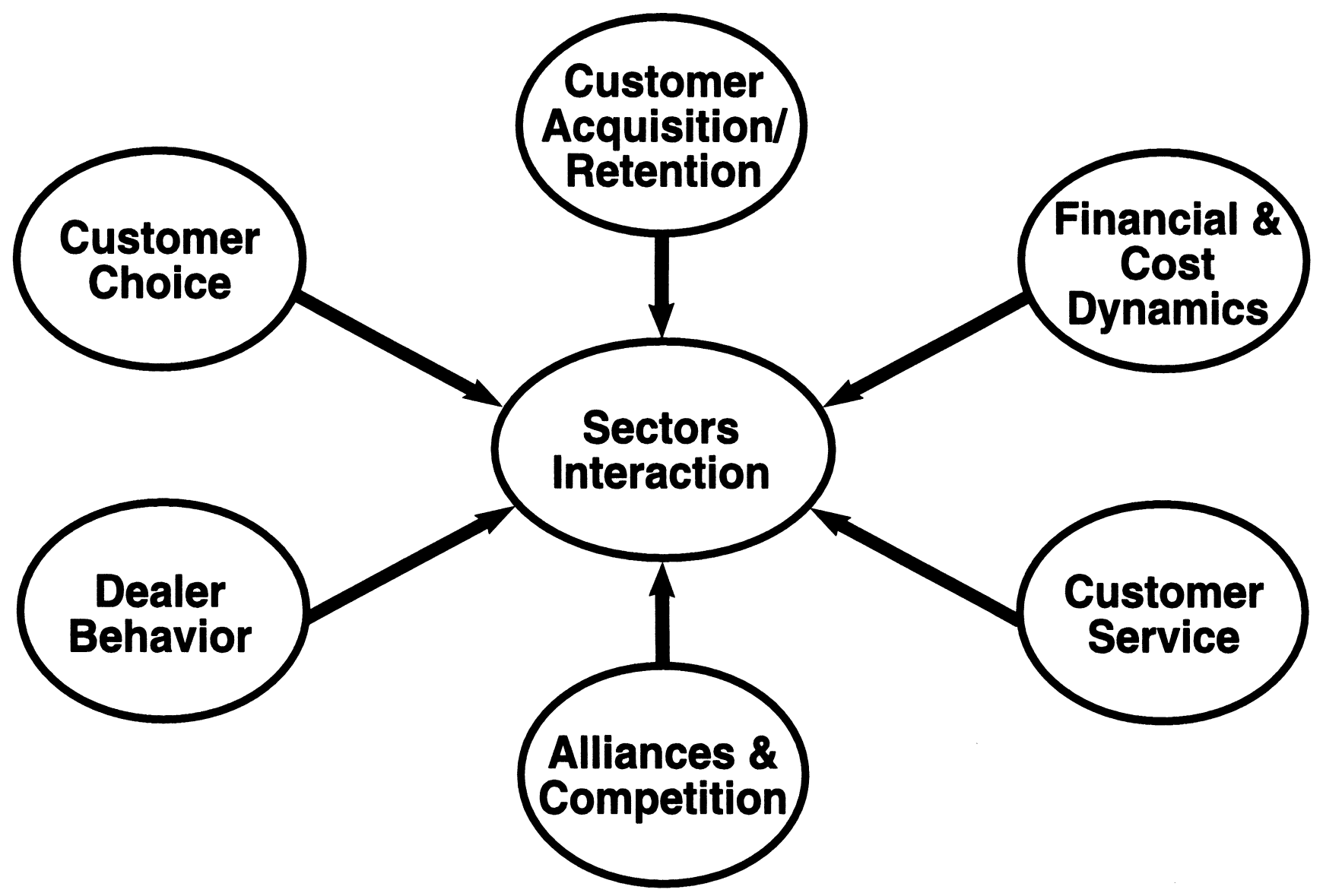

Figure 4: The simulation model of the telematics industry included multiple, interacting sectors.

impact of decisions that would affect GM's acquisition and retention of subscribers.

The detailed model structure begins with the simple relationship that determines the number of new subscribers:

$$
N S=T R^{*} V \text {, }
$$

where NS is the number of new subscribers added during a time period, $T R$ is the take rate (a fraction between zero and one), and $V$ is the number of new vehicles on which OnStar is available. $V$ can include both GM and non-GM vehicles, depending on GM's policy toward alliances with other vehicle manufacturers.

The modeling of the take rate (TR) begins with ideas developed in the product diffusion literature. The take rate is the product of customer awareness and customer choice:

$$
T R=A^{*} C,
$$

where $A$ is the fraction of new car buyers who have top-of-mind awareness of OnStar, and $C$ is the fraction of new-car buyers who choose to subscribe to OnStar conditional on awareness. The product-diffusion literature suggests that the two factors that drive awareness are the coefficients of internal and external influence. The coefficient of internal influence usually represents the effect of word-of-mouth communication on sales. We believed, and the data have subsequently confirmed, that word-of-mouth would be an important factor in generating awareness for OnStar.

Several published metastudies of estimated diffusion models were helpful in calibrating the word-ofmouth effect (Mahajan et al. 1995, Sultan et al. 1995). We had no direct evidence about the magnitude of the effect in the telematics market, but we used published 
BARABBA ET AL.

The General Motors OnStar Project

studies to construct a range of estimates that we thought were reasonable. The ranges were the basis for extensive sensitivity analysis on word-of-mouth and other uncertain parameters.

The coefficient of external influence represents the effect of the firm's marketing effort on product adoption. In several product-diffusion studies, researchers have modeled the external effect as an increasing function of spending on marketing. We used a similar approach and used the metastudies to calculate reasonable bounds for the magnitude of the effect. We also

\section{We believed word-of-mouth would be an important factor in generating awareness.}

consulted with internal GM marketing experts and outside advertising experts to estimate how much OnStar would have to spend to reach different levels of awareness. Consistent with previous studies, the relationship between marketing spending and awareness exhibited diminishing returns.

The choice variable is the conditional probability that a new-car buyer will subscribe given that OnStar is available on the vehicle. The probability of the buyer's choosing OnStar depends on the utility of OnStar relative to the utility of alternative uses of the money and the utility of any available competing systems. We modeled the probability of choice with the logit-choice function that is commonly used in marketing studies (Meyer and Johnson 1995). We derived the utilities we used to calibrate the logit choice model from a consumer research study.

The choice function included the effects of network externalities. Writers on the economics of new-product diffusion make a strong case for the importance of network externalities or positive-feedback effects (Shapiro and Varian 1999). Positive-feedback effects are the increases in the value of the service for all existing users as additional users adopt the service. We were aware of these effects and asked an outside consulting firm to search for examples relevant to the OnStar situation. Its research turned up several examples that were useful primarily for identifying potentially important positive-feedback processes. The examples were not useful, however, for projecting the number of OnStar subscribers or estimating revenue and cost flows.

We believed that three positive-feedback processes could be important in the telematics industry. Each process could create positive feedback, but their implementation required managerial attention and effort. The first process concerned creation of new OnStar applications. In 1997, OnStar was limited to the core safety and security features. Although these features were extremely valuable, the market research showed they would not be enough to drive widespread penetration. From the beginning, we recognized that GM could never find and build internally the myriad applications that OnStar would need. Alliances with important new-economy and old-economy players would be crucial.

We considered the factors that would make GM an attractive partner to prospective content partners and the factors that would make it economic for GM to invest in partnerships. Examples of potential content partners included Fidelity Investments and several vehicle-insurance companies. For both old- and neweconomy firms, partnerships become much more attractive as the installed base of subscribers grows. The classic example of how applications partnerships can create positive feedback is Microsoft Windows. Applications developers wrote applications for Windows that made Windows more valuable. Increased value increased the number of customers buying Windows, which, in turn, made developing further applications more attractive.

We hypothesized that a similar process could occur with OnStar. The economic dynamics of a recently announced OnStar alliance for providing real-time personalized traffic information demonstrates this process. Market research revealed that consumers want personalized traffic information and that providing it could be the telematics killer application. Traffic information requires both GM and its partner to make major up-front investments. Providing the traffic information feature is economically unattractive with a small installed base because the average cost per subscriber would be much too high. The economics become very attractive as the installed base reaches several million. The alliance mechanism forms a positive feedback because the availability of the traffic service 
BARABBA ET AL.

The General Motors OnStar Project

makes OnStar more attractive to car buyers. In turn, additional subscribers make OnStar alliances more lucrative for all involved.

Quantifying the magnitude of the positive-feedback processes was a challenge. We were tempted to conclude that we could not accurately quantify these mechanisms and to leave them out of the formal modeling. We decided to try to quantify the alliance feedback, because historical examples suggested that they could be critical to OnStar's development, and because the strength of the positive feedback is affected by many other variables, such as pricing and spending on marketing. Omitting the mechanisms from the model would greatly distort the effects of alternative pricing and marketing-investment policies.

To quantify these effects, we considered a long list of potential services and partners. We used GM managers' judgment and financial data to estimate how the

\section{The AMIC standards could be a double-edged sword for OnStar.}

number of subscribers would influence the economics of the different services. We used a combination of market research and judgment to estimate how consumers would value additional services. We used sensitivity analysis to determine how the system would react to different values of uncertain parameters.

The second positive-feedback process concerned the dynamics of third-party sales of OnStar. Third-party sales would be installations of OnStar through stereo stores; electronics retailers, such as Circuit City and Best Buy; and discount retailers, such as WalMart. Previous research reported in the marketing literature isolated a positive-feedback process in which products with high sales and large market shares receive more display space and attention at retailers, which, in turn, further increases market share and sales (Reibstein and Farris 1995).

Third-party distribution is the tool for reaching the 200 million existing vehicles and the 70 percent of new car buyers who buy competitors' cars. The viability of third-party distribution depends on the cost and ease of retrofitting vehicles with OnStar hardware. We already knew that replicating the existing dealer- installation procedure would be too costly and would generate few sales. Also it would be time-consuming and expensive to modify OnStar to interface with multiple car electronics systems. GM acted to reduce the cost of third-party installation by sponsoring the Automotive Multimedia Interface Consortium (AMIC). The AMIC is in the process of setting standards for connecting to vehicle electrical systems. The standards will enable any manufacturer of telematics systems to connect to the vehicle electronics systems of any automobile without compromising the integrity and safety of any of the systems.

The AMIC standards could be a double-edged sword for OnStar. On one side, they enable businesses to connect OnStar to competitors' cars. On the other side, they allow businesses to connect future competitors' telematics systems with GM cars. The AMIC standards increase the value of building a viable largescale telematics system because the consumer value initially created for GM cars can be extended to other platforms.

The third positive-feedback process concerns including other vehicle manufacturers in the OnStar alliance.

We believe that our project is one of the first published applications to analyze the strategic implications of network effects in a real-life situation. Although the importance of network effects is clear, ex post, from many historical case studies, few newproduct models actually incorporate them. Gupta et al. (1999, p. 327) wrote the following:

\footnotetext{
Network effects have attracted significant attention from economists in recent years. However, marketing scientists have been slow to respond to the growing importance of this phenomena in new product adoption. For instance, most new product models in the marketing science literature assume that new products are autonomous and that the adoption of new products is not affected by the presence or absence of complementary products. These assumptions are being called into question in almost every durable product market in the Network Economy, where firms rarely act alone to create new products.
}

\section{Customer Choice}

To calibrate the customer-choice sector, GM commissioned a conjoint study to estimate how consumers would respond to different subscription fees, initial 
BARABBA ET AL.

The General Motors OnStar Project

costs, and combinations of features (Reibstein and Farris 1995). The sample for the conjoint study was 621 new-car buyers. In the conjoint study, researchers estimated the utility of 13 potential attributes of the OnStar system, including route guidance, remote vehicle diagnostics, traffic information, initial price, and monthly subscription fees.

The study showed that consumers could be divided into six market segments. The segments had different utilities for the service attributes and prices. In the customer acquisition sector, we calculated take rates separately for each market segment.

We used the market study to calibrate the consumerchoice decision. For example, we tested the impact of different attribute combinations and prices on longterm OnStar penetration and profitability. We also experimented with alternative price trajectories, such as skim and penetration pricing. Skim pricing involved installing OnStar on a few expensive GM models, such as Cadillac, and charging a premium price for OnStar. Penetration pricing involved installing OnStar on all GM models and charging a low price that would maximize the take rate.

\section{Vehicle Manufacturer Alliances}

The option of offering OnStar to other vehicle manufacturers emerged early in the project. Clearly, enrolling other manufacturers could be beneficial. First, increasing the vehicles in the alliance would create a large OnStar installed base and strengthen positivefeedback processes. Second, GM could collect licensing fees for the use of OnStar. The disadvantage of making OnStar generally available would be that GM would lose a competitive weapon for selling vehicles.

We evaluated the option of offering OnStar to other manufacturers by including an additional positivefeedback process in the model. Manufacturers had four options in the telematics market: do nothing, start their own services, join the OnStar coalition, or join another coalition. The probability that a manufacturer (other than GM) would choose one of the options was given by

$$
P=f(S, V, T, C, F, M),
$$

where $S$ is the number of subscribers for a specific service (OnStar, Ford, and so forth), $V$ is the number of vehicles that offer a service, $T$ is the take rate for a service, $C$ is the estimated investment cost of setting up a telematics service, $F$ is the fee charged by the coalition for using the service, and $M$ is the manufacturer that sponsors the coalition. In the model, we assumed that the probability of choosing an existing service increased with increases of $S, V, T$, and $C$. A large base of subscribers $(S)$ and a high take rate $(T)$ demonstrate that the service is successful and will be more successful in the future. Other manufacturers would prefer to enroll in a successful coalition. In addition, a high take rate shows that consumers want the service and that manufacturers without a service are at a competitive disadvantage. If the sum of the $V s$ across coalitions is large, most vehicles offer telematics services and the holdouts are under pressure to join one of the coalitions. A high cost of establishing a service $(C)$ makes it

\section{The analysis showed that the cost- focused strategy would cause the effort to fail.}

disadvantageous to create a new service and more advantageous, especially for small manufacturers, to join a coalition. High fees $(F)$ for participating in a coalition reduce the probability that an outside manufacturer will join. Finally, some manufacturers will be very hesitant to partner with other manufacturers, such as Ford with GM, so that the identity of a coalition sponsor $(M)$ influences the probability of an alliance.

Original equipment manufacturers (OEMs) benefit greatly by joining an OnStar coalition. First, replicating the GM system would be very costly for auto manufacturers with much lower volumes than GM, especially if GM were able to exploit positive feedback and add high-value services. Second, assuming that consumers find telematics services attractive (market research supports the conclusion), if several competing OEMs were to join the coalition, the holdout competitor could lose precious market share in the vehicle business. Finally, if OnStar were to build a credible third-party distribution system with the AMIC standard, OnStar would have access to the competitors' cars even if they didn't join the coalition. OEMs could conclude that their best interests lie in joining the coalition and cutting the best deal possible, instead of 
BARABBA ET AL.

The General Motors OnStar Project

letting GM capture their customers through the aftermarket.

For each major vehicle OEM, the team considered the costs and benefits of partnering with OnStar from the perspective of that competitor. Our reasoning process was similar to that of estimating competitor payoffs in a game-theory analysis. During each time period, the model calculated the probability that a manufacturer would choose one of the four options; once a manufacturer chose to join a coalition or to start its own service, it could not change its decision.

The alliance decision structure creates another positive-feedback process. Additional partners increase the value of the system through multiple mechanisms, such as word-of-mouth and additional applications. In turn, a more valuable system attracts new subscribers and additional partners. We did not believe that these processes would be so strong as to create a single system for the whole vehicle industry. We acknowledged that some competitive automakers would be so averse to a GM-sponsored system that they would never join an alliance.

\section{Customer Service}

The customer-service sector represented demands for customer service and the acquisition and retention of service capacity. Poor customer service could restrain the long-run growth of OnStar. Rapid subscriber growth increases the demand on the call centers. OnStar must be able to match customer-service capacity to demand or, beyond a point, the quality of its customer service will deteriorate. Common sense suggests and the literature on customer service confirms that customers' poor experiences with service reduce the attractiveness of the service, reduce the firm's acquisition of new subscribers, increase churn, and generate negative word-of-mouth.

A firm can minimize the negative effects of inadequate customer-service capacity by choosing the right customer-service policy. Often, firms run their call centers with a cost mentality. Their objective is to minimize the cost of the call center by paying low wages, limiting the time spent per call, and always running at close to full utilization. The model-based analysis showed that the cost-focused strategy would cause the entire OnStar effort to fail. OnStar depends on a staff of intelligent, well-trained service personnel to provide excellent service during difficult situations, such as car wrecks and serious illness. It takes time to recruit and train people who are up to the task. Consequently, OnStar has adopted a policy of purposely overstaffing the call center in order to build customer-service capacity in advance of expected demand. The overstaffing policy gives service employees opportunities to learn systems and scenarios before they have full customer-service responsibilities. This policy is the only one that is consistent with the strategy of building a large installed base, and we estimate that it will pay for itself several times over in terms of lower churn rates and positive word-of-mouth.

\section{Model Analysis of the Factory Installation Decision}

GM's most important decision was whether to factoryinstall OnStar in new vehicles. Factory installation has several advantages. First, factory installation eliminates the $\$ 1,300$, two-day dealer-installation process that greatly reduced the take rate. Second, factory installation eliminates the need for dealers to convince

\section{OnStar adopted a policy of purposely overstaffing the call center.}

buyers to purchase OnStar as an option. The disadvantage of factory installation is that the hardware is somewhat expensive and, if a new vehicle buyer does not subscribe to OnStar, GM gains no revenue from the factory installation.

Factory installation directly affects cost by eliminating the cost of dealer installation (Figure 5). Factory installation also increases the number of cars with OnStar available and, for a given take rate, the number of OnStar subscribers. Increases in the number of subscribers strengthen the positive-feedback processes that influence alliances and the development of applications. Specifically, additional subscribers increase the attractiveness of creating OnStar applications and the attractiveness for other OEM's of joining the OnStar alliance. Additional applications and a larger alliance both increase the number of new subscribers. 


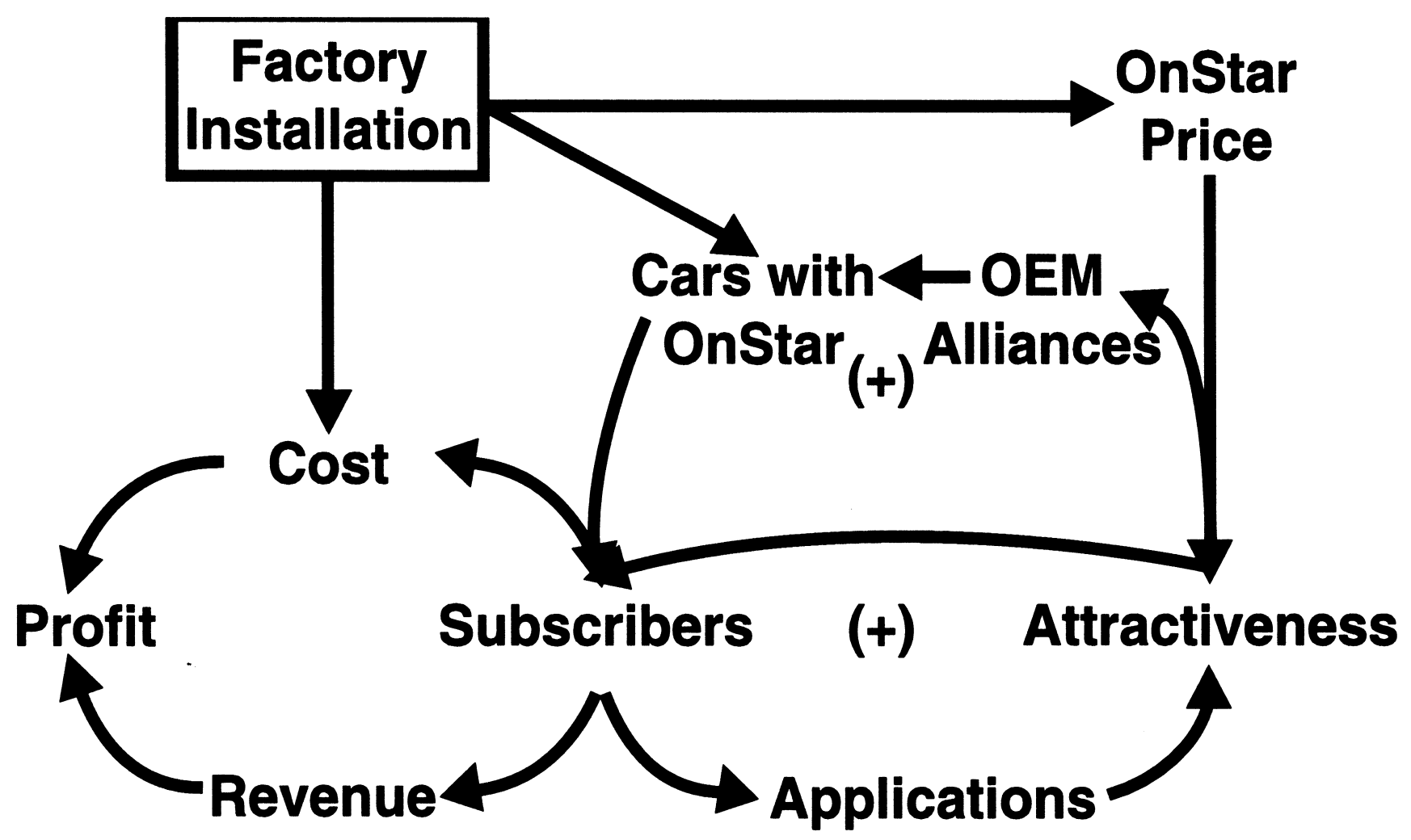

Figure 5: The positive feedback loops that drive OEM alliances and applications amplify subscriber growth.

We compared the number of subscribers for 100percent factory installation with a baseline in which OnStar was a car option (Figure 6). Although the difference between the two scenarios is fairly small during the first two years, the positive-feedback processes cause a dramatic gap in the eighth through 10th years. Profits are low during the first three years in the factory-installation case because of the high initial cost of installing OnStar in all GM vehicles. In subsequent years, revenue and profit are much higher in the factory-installation case than in the base case because total subscription fees increase and the average cost per subscriber drops.

The simulation model was also an essential tool for sensitivity analysis. We varied uncertain parameters one by one and in combinations to determine whether doing so would change the best strategic option. Finally, we ran Monte Carlo simulations that varied all the uncertain parameters together. We found that the superiority of the factory installation strategy was robust against almost all parameter variation (Figure 7).
Financial, Organizational, and Societal Impacts

In late 1997, the project team recommended a very aggressive strategy that included factory installation on all GM vehicles, recruitment of other manufacturers into the OnStar system, and making the first year of service free. In addition, we recommended that GM aggressively pursue alliances with content partners, such as a major cell-phone networks, Fidelity Investments, and Dow Jones Publications. GM's senior managers agreed to the aggressive strategy, and implementation is proceeding today. Many people are familiar with OnStar through GM's well-known Batman advertising campaign.

Vince Barabba, GM's senior executive for strategy, and Ron Zarrella, the president of GM at the time, believe that the modeling process greatly influenced GM's strategic choices for OnStar. Vince qualifies his belief in the utility of models by proclaiming Barabba's Law: "Never say the model says." Vince's point is that 


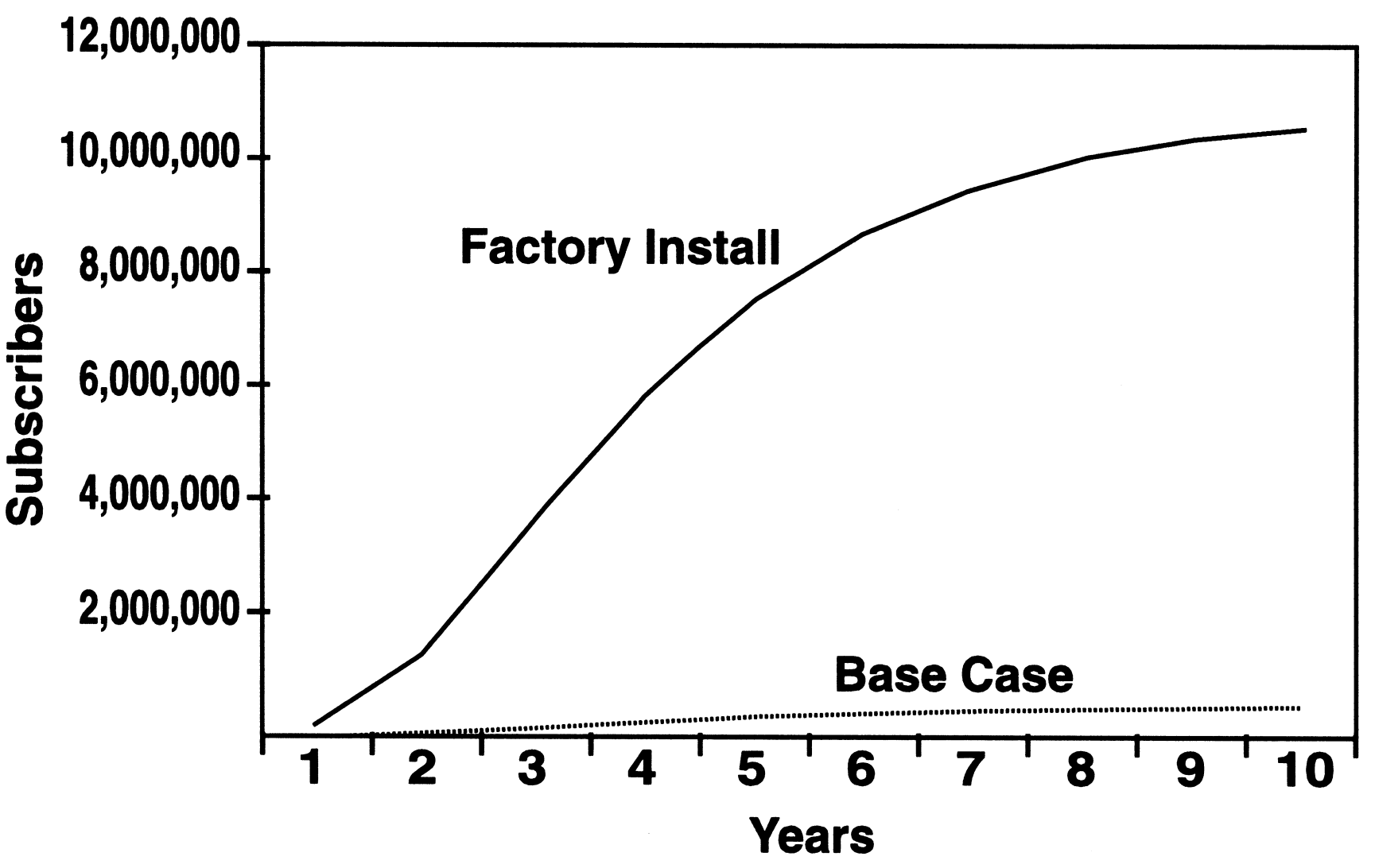

Figure 6: The factory installation strategy generated far more subscribers than the incremental base case strategy.

people, not models, have points of view that are formed by experience and can be clarified and improved by simulation models. Especially for strategic choices, models can never be more than aids in reaching sound judgments.

\section{Financial Impacts}

Through 2001, the implementation of the OnStar business strategy has progressed very much as expected. As of fall 2001, OnStar has more than two million subscribers and an 80 percent share of the telematics market. The number of subscribers is growing rapidly. No other vehicle manufacturer is expected to launch a competitive system until 2003 at the earliest. The largest competitor is a small independent firm that has about 80,000 subscribers.

Competitors will have difficulty replicating OnStar's business. OnStar has benefited from learning during the past four years. Creating a system like OnStar is much more complex than putting a modem and GPS in the car and contracting with a call center. The system must be capable of handling millions of subscribers and never fail because of the high stakes involved in auto accidents and emergencies. Many dot-com firms have learned how difficult it is to expand missioncritical IT systems to accommodate millions of users. The system must be flexible enough to add new services quickly without disrupting existing features.

GM has forged alliances with vehicle manufacturers that account for over 50 percent of vehicle sales. GM's partners include Toyota, Honda, VW-Audi, and Subaru. Honda and Toyota are initiating factory installation on their Acura and Lexus models, respectively.

GM has also enrolled an impressive list of content partners. WestWood One, a prominent radio company, has partnered with OnStar to provide real-time traffic information. Dow Jones provides the Wall Street 
BARABBA ET AL.

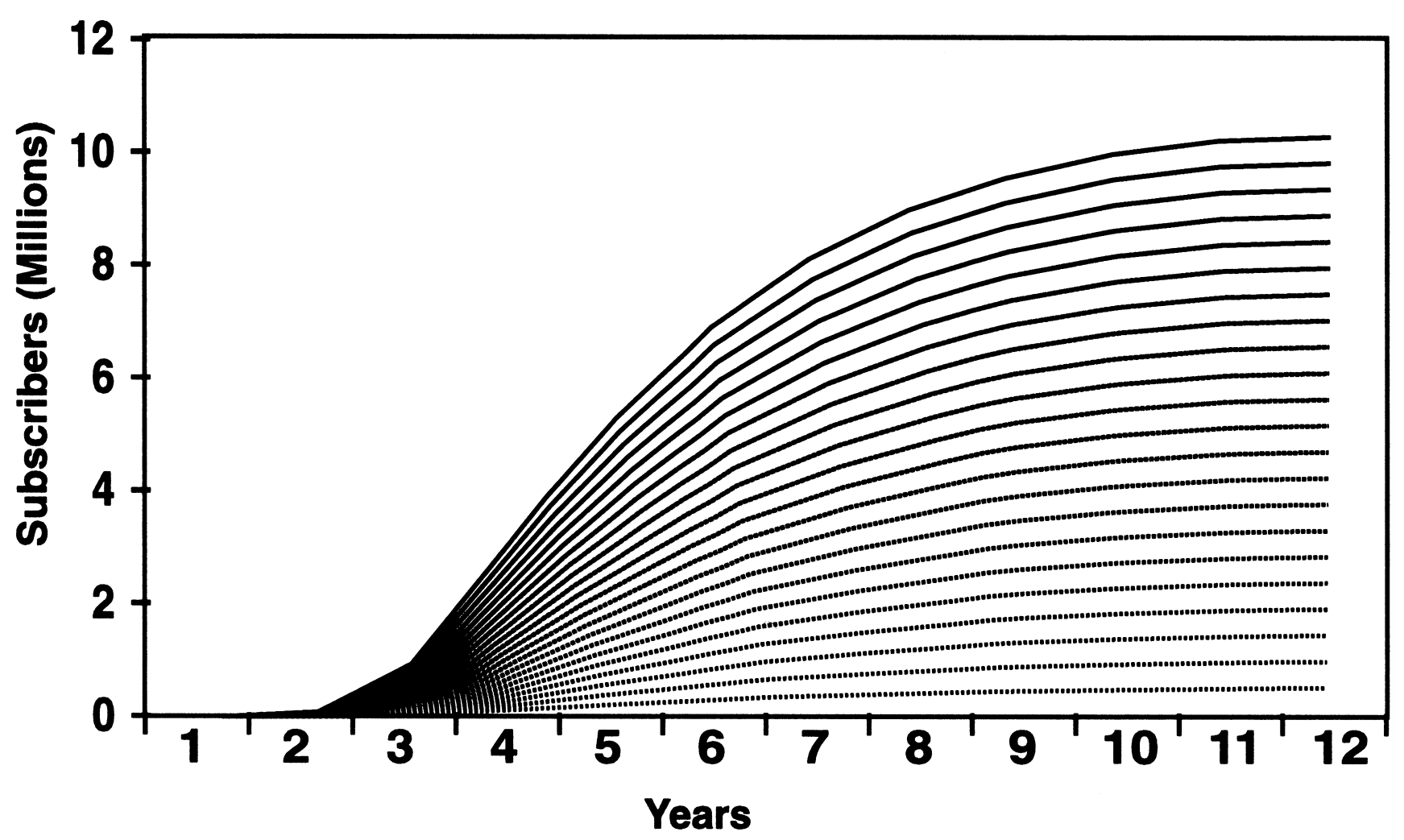

Figure 7: The simulation model was used to generate multiple scenarios for subscribers and other important variables.

Journal, which is read to car occupants by the OnStar virtual advisor. The virtual advisor downloads the requested content and reads it to the driver through the vehicle's sound system. The virtual advisor also allows users to trade securities from the vehicle through Fidelity Investments. OnStar receives approximately five proposals per week from prospective service partners.

OnStar is on track for financial success. In early November 2001, Ron Zarrella, then president of GM, forecast that OnStar would break even by 2003 and would generate major cash flows thereafter. Investment bankers have valued OnStar at between $\$ 4$ and $\$ 12$ billion if it were to be spun off as an independent business (Merrill Lynch 2000, Lapidus 2000, Martiliotti 2000).

\section{Organizational Impacts}

The OnStar project contributed to creating a new enterprise mental model for GM. The company has had a mental model of the vehicle business as a transaction in which GM creates value by the transaction of selling a vehicle. This mental model, or theory of the business, served GM well for many years, but intense competition has reduced its effectiveness in recent years.

The new mental model augments the transactions revenue with a stream of revenue from service businesses like OnStar (Figure 8). Examples of other service businesses are enhanced vehicle service and repair, and vehicle insurance. The annuity revenue and cash flow from services should greatly improve GM's market value. Investment banking studies have estimated that GM could generate several billion of extra earnings annually from greater participation in service businesses. In addition, the service and vehicle businesses form a positive-feedback loop in which healthy service businesses make the vehicle business more valuable, and a healthy vehicle business makes the service businesses more valuable. OnStar was the first step and a critical component in the process of connecting the vehicle business and service businesses. 


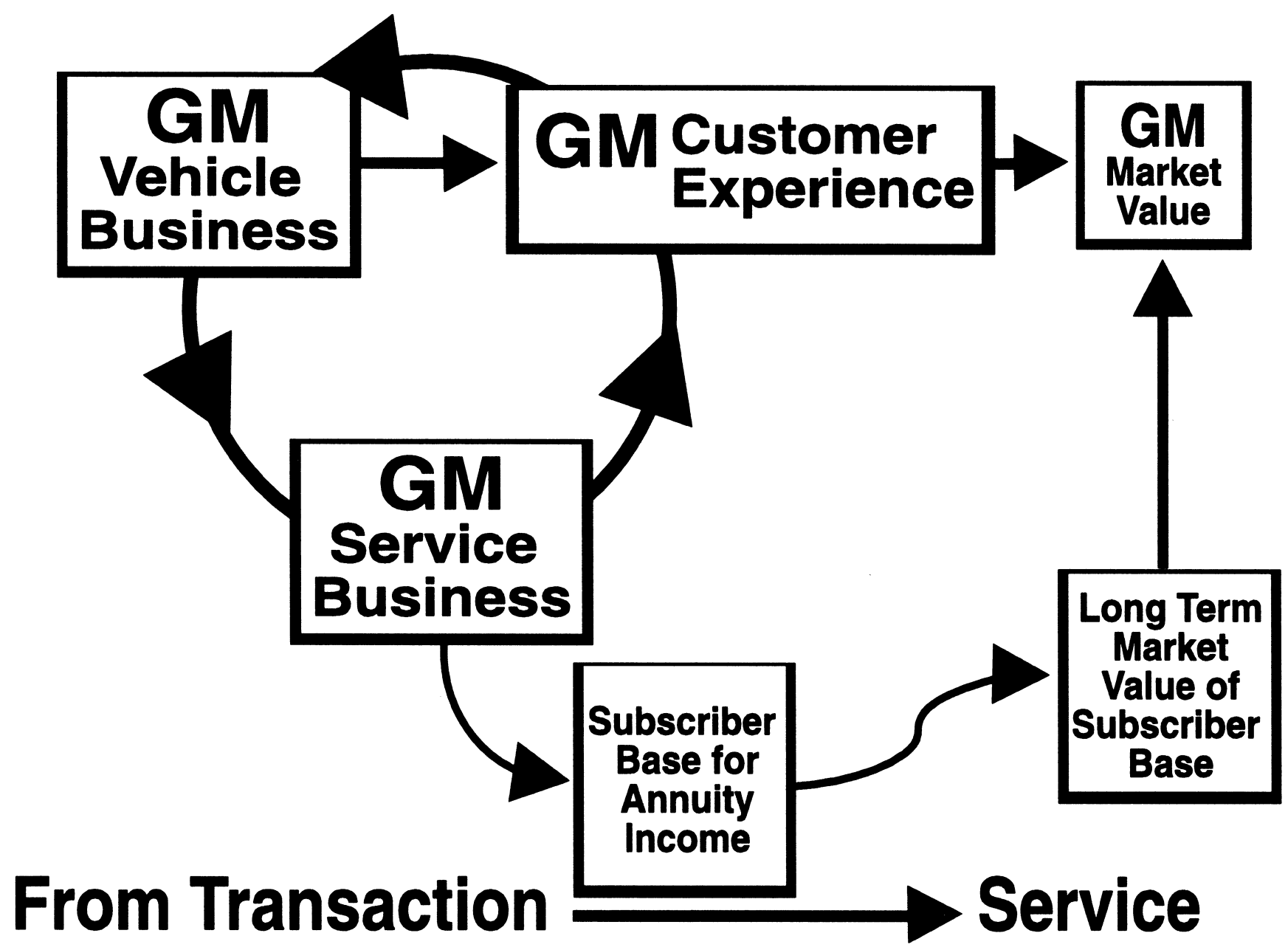

Figure 8: The new GM enterprise mental model increases market value by managing the dynamic interaction between the vehicle and service businesses.

\section{Societal Benefits}

The first societal benefit of the OnStar project is the creation of the new telematics business. The telematics industry did not exist before GM implemented its strategy. Today, Wall Street analysts project that the industry will grow to $\$ 12$ billion over the next 10 years. In addition, such services as real-time traffic information will increase productivity by helping to reduce traffic congestion.

By far, OnStar's most important contribution is saving lives. OnStar answers thousands of emergency calls each month and has often made the difference between life and death. Studies in emergency medicine show that reducing response time by only five minutes can enormously increase survival probabilities. OnStar's impact on the lives of thousands of people can be partly measured by the amazing letters that GM receives every day. These letters tell remarkable stories of how rapid emergency response has prevented death and serious injury. As more manufacturers make telematics services available, survival rates should increase further.

\section{Acknowledgments}

The authors thank Lyle Wallis for his ongoing help in developing and expressing the concepts in this paper. They also thank John Sterman and Nelson Repenning of MIT for their ideas and the use 


\section{BARABBA ET AL.}

of their classes as test beds for our presentation. Bill Stripling provided valuable coaching assistance in developing the Edelman presentation. Rebecca English Paich was very helpful in editing the paper and improving the clarity of the writing.

\section{References}

Gupta, Sachin, Dipak C. Jain, Mohanbir S. Sawhney. 1999. Modeling the evolution of markets with indirect network externalities: An application to digital television. Marketing Sci. 18(3) 396-416.

Gurumurthy, Kalyanaram, William T. Robinson, Glen L. Urban. 1995. Order of market entry: Established empirical generalizations, emerging empirical generalizations and future research. Marketing Sci. 14(3) Part 2, G212-G221.

Lapidus, Gary. 2000. Gentlemen start your engines. Goldman Sachs, January.

Mahajan, Vijay, Eitan Muller, Frank M. Bass. 1995. Diffusion of new products: Empirical generalizations and managerial uses. Marketing Sci. 14(3) Part 2, G79-G88.

Martiliotti, Domenic. 2000. Can GM finally deliver the product? Bear Stearns Equity Research, December.

Merrill Lynch Equity Research. 2000. General Motors Corp. April.

Meyer, Robert, Eric J. Johnson. 1995. Empirical generalizations in the modeling of consumer choice. Marketing Sci. 14(3) Part 2, G180 G189.

Reibstein, David J., Paul W. Farris. 1995. Market share and distribution: A generalization, a speculation, and some implications. Marketing Sci. 14(3) Part 2, G190-G202.

Shapiro, Carl, Hal Varian. 1999. Information Rules. Harvard Business School Press, Cambridge, MA.

Sultan, Fareena, John U. Farley, Donald R. Lehmann. 1990. A metaanalysis of applications of diffusion models. J. Marketing Res. 27(1) 70-77. 